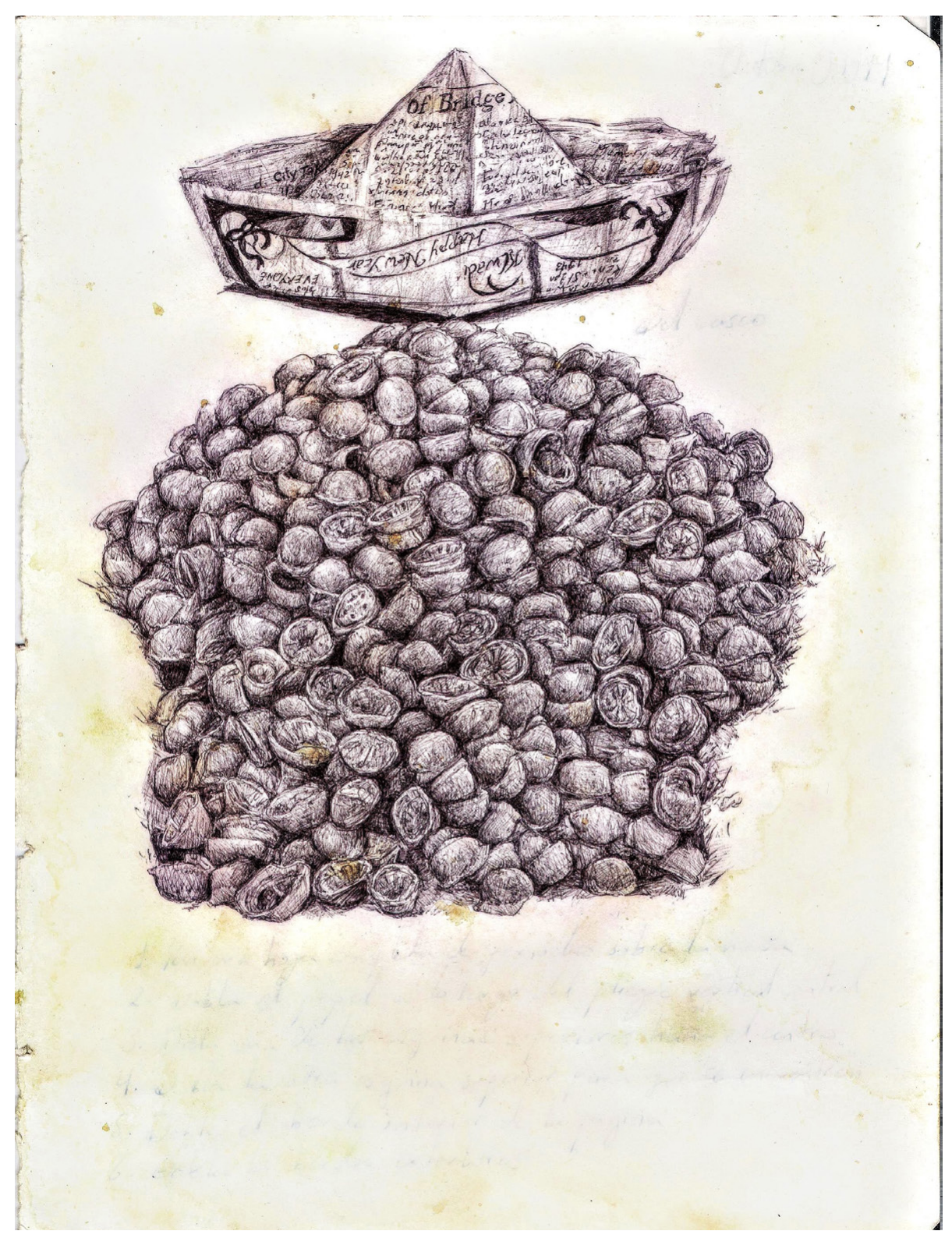

Sebastián Zea Quintero

Sin título

De la serie Del juego y el hombre Lápiz sobre papel

2017

Medellín 


\title{
Identidades políticas y justicia transicional. Las representaciones sobre los desaparecidos en el Juicio a las Juntas Militares de 1985 en Argentina*
}

\author{
Diego Galante (Argentina)**
}

\section{Resumen}

En este artículo se analizan las modalidades de construcción de las identidades de las víctimas del terrorismo de Estado durante las audiencias orales del Juicio a las Juntas Militares de 1985 en Argentina. Apunta a esclarecer las formas en que el contexto judicial y el contexto cultural y político interactuaron en esos procesos de significación, elementos que investigaciones antecedentes han abordado separadamente. Se defiende la tesis de que se produjeron articulaciones y tensiones entre el género jurídico, el contexto judicial, los discursos del orden moral y la coyuntura cultural y política, y que el conocimiento sobre esa experiencia puede echar luz sobre los desafíos que se presentan en otros procesos de justicia transicional. Se adopta una metodología cualitativa, basada en el análisis temático de registros judiciales, entrevistas en profundidad y materiales de prensa. Entre los principales hallazgos están las dos tendencias complementarias en el caso de estudio: la justicia transicional como instancia de consagración simbólica de la figura del sujeto de derecho y como campo de actualización y disputa de sentidos sociales no regidos por la escena judicial.

\section{Palabras clave}

Memoria; Justicia Transicional; Identidades Políticas; Desaparición Forzada; Argentina.

Fecha de recepción: noviembre de 2019

- Fecha de aprobación: abril de 2020

\footnotetext{
* El artículo se deriva del proceso de investigación doctoral El Juicio a las Juntas Militares: derechos humanos, memoria y ciudadanía en la Argentina (1983-2013), Facultad de Ciencias Sociales, Universidad de Buenos Aires, tesis defendida en 2014. Agradezco las observaciones y sugerencias realizadas por los pares evaluadores anónimos.

** Licenciado en Sociología. Magíster en Ciencia Política. Doctor en Ciencias Sociales. Miembro del Grupo de Estudios sobre Historia Reciente y Memoria Social, Instituto de Investigaciones Gino Germani, Facultad de Ciencias Sociales, Universidad de Buenos Aires, Argentina. Correo electrónico: diegalante@hotmail.com - Orcid: 0000-0003-4507-0857
} 


\title{
Cómo citar este artículo
}

Galante, Diego. (2020). Identidades políticas y justicia transicional. Las representaciones sobre los desaparecidos en el Juicio a las Juntas Militares de 1985 en Argentina. Estudios Políticos (Universidad de Antioquia), 58. pp. 87-110. DOI: 10.17533/udea.espo.n58a05

\section{Political Identities and Transitional Justice. Representations of the Desaparecidos in the Trial of the Military Juntas of 1985 in Argentina}

\begin{abstract}
This article analyzes the modalities of construction of the identities of the victims of State terrorism during the oral hearings of the Trial to the Military Juntas of 1985 in Argentina. It aims to clarify the ways in which the judicial context and the cultural and political context interacted in these processes of meaning; elements that have been addressed separately in former researches. The study states that there were articulations and tensions between the legal genre, the judicial context, the discourses of the moral order and the cultural, and political situation. Accordingly, the study also states that the knowledge of this experience can shed light on the challenges that arise in other transitional justice processes. A qualitative methodology is adopted, based on the thematic analysis of judicial records, in-depth interviews, and press materials. Among the main findings are the two complementary trends in the case study: justice.
\end{abstract}

\section{Keywords}

Memory; Transitional Justice; Political Identities; Forced Disappearance; Argentina. 
Identidades políticas y justicia transicional. Las representaciones sobre los desaparecidos...

\section{Introducción}

En 1985, durante la última transición a la democracia en Argentina, se llevaron a cabo las audiencias orales y públicas del juicio conducido contra nueve excomandantes de las Juntas Militares de la dictadura saliente por las violaciones sistemáticas de los derechos humanos cometidas en el ejercicio del poder. Concebido como un momento central de la política y la justicia transicional, el proyecto proponía evaluar las responsabilidades penales de los máximos responsables del régimen de desaparición de personas implementado en marzo de 1976.

El juicio fue llevado ante la Cámara Federal y en 1986 recibió sentencia definitiva de la Corte Suprema (República Argentina, 1986). Promovido por el Decreto Presidencial 158/83 en diciembre de 1983 y tras primera instancia ante el fuero militar (Nino, 2006), entre abril y octubre de 1985 la Cámara Federal recogió más de ochocientos testimonios, dando a conocer su sentencia el 9 de diciembre de ese mismo año (Causa 13/84 de 1985). El juicio se inscribió, a su vez, en un proyecto transicional de justicia impulsado por el gobierno de Raúl Alfonsín (Galante, 2017), el cual incluía, además, la prosecución penal, aunque limitada, de otros perpetradores y el juzgamiento de los líderes sobrevivientes de las principales organizaciones de la izquierda revolucionaria argentina de la década de 1970. Jorge Videla y Emilio Massera, emblemas del gobierno dictatorial, fueron condenados a cadena perpetua; Roberto Viola a diecisiete años de prisión; Armando Lambruschini recibió ocho años de condena; Orlando Agosti cuatro años y medio; Leopoldo Galtieri, Omar Graffigna, Jorge Anaya y Basilio Lami Dozo fueron absueltos (Nino, 2006; Sancinetti, 1988; Ciancaglini y Granovsky, 1995).

El acontecimiento representa el antecedente político de mayor relevancia en el ámbito regional para los procesos de justicia por delitos de lesa humanidad que en la última década y media, y con grados variables de desarrollo, se desenvuelven por los crímenes de las dictaduras de las décadas de 1960 y 1970 en el Cono Sur —Chile, Uruguay, Brasil, Paraguay; y su segundo ciclo en Argentina-, y otros crímenes masivos más recientes — Guatemala, El Salvador y Perú-. Constituye una valiosa fuente para comprender los heterogéneos procesos, desafíos, obstáculos y potencialidades que los mecanismos transicionales de justicia pueden aportar a distintas sociedades que, aunque a partir de experiencias disímiles, debaten mecanismos de transición tras periodos prolongados de violencia política. En particular, este 
artículo concentra los esfuerzos en poner de manifiesto las tensiones políticas que dichos eventos pueden dar cuenta a partir de la construcción social que escenifican sobre las víctimas.

En Argentina, el evento penal de 1985 se convirtió en un elemento preponderante en la escena política del periodo y tuvo múltiples repercusiones en el ámbito local e internacional. Concentró fuertemente la atención y opinión pública en Argentina (Arfuch, 2008), se convirtió en un eje central de la escena política local a través del cual se actualizaban los debates sobre el sentido del pasado y de la democracia recientes (Galante, 2014; 2015), y consolidó un conocimiento cabal sobre las distintas etapas del régimen de desaparición de personas, las cuales incluyeron el secuestro, la tortura, la detención en un centro clandestino, la muerte, la eliminación de los cadáveres y de las pruebas físicas de los delitos.

Desde las ciencias sociales, se ha analizado su rol como medio para la restauración simbólica del Estado y del sujeto de derecho en la Argentina de la transición (Kaufman, 1991; González, 2004), y como un elemento dinamizador de la oposición entre democracia y dictadura forjada en el discurso político de esos años (Aboy Carlés, 2001; también ha sido destacado su rol como

[ 90 ] suceso que posteriormente fue extrapolado al exterior, creando una «cascada de justicia», la cual transformó la práctica del derecho, el tratamiento de las violaciones a los derechos humanos y las relaciones internacionales a escala global (Sikkink, 2011).

Sin perjuicio de lo anterior, el acontecimiento judicial de la década de 1980 se produjo en un contexto político y cultural atravesado fuertemente por las huellas del autoritarismo; y a pesar del crecimiento público de las denuncias en clave humanitaria, la estigmatización social existente acerca de los eventuales compromisos políticos contestarios de las víctimas de la represión, entre otras características propias de la cultura política de la transición (O'Donnell, 1997; Acuña et al., 1995; Crenzel, 2008; Feld y Franco, 2015).

En ese marco contextual, a lo largo de las audiencias orales se incorporaron diversos elementos propios de otros discursos culturales en circulación, mediados — pero no dominados- por la función judicial. Entre esos discursos, en las voces de los militares y otros actores políticos afines, se manifestó el «consenso antisubversivo», consolidado durante la 
Identidades políticas y justicia transicional. Las representaciones sobre los desaparecidos...

dictadura —basado en la convicción sobre la legitimidad y necesidad de la masacre represiva (Canelo, 2008)—y en distintas estrategias públicas de reivindicación por lo actuado en la «guerra antisubversiva» (Salvi, 2015). Por otro lado, las denuncias de los crímenes se encontraron también mediadas por la difusión en diversos ámbitos sociales del imaginario conocido como la «teoría de los dos demonios» — basado en la condena del «terrorismo de cualquier signo»—, la cual proponía la ajenidad de las víctimas a esos grupos propuestos en enfrentamiento, al tiempo que ocluía las responsabilidades de la sociedad política y civil en los crímenes o sus objetivos políticos regresivos (Franco, 2015).

El objetivo de este artículo es focalizar el análisis en las representaciones sobre las identidades de las víctimas del terrorismo de Estado que fueron puestas en escena durante el proceso penal, con particular atención en la dimensión política de los conflictos implicados en esos procesos de definición. A tal efecto, se toman en consideración las reflexiones propuestas por Stuart Hall sobre la noción de identidad y los procesos de identificación en las sociedades contemporáneas (Hall, 1995; Hall y du Gay, 2003). Se asume, consecuentemente, la noción de identidad como un punto de articulación entre los discursos y prácticas que interpelan a los individuos, «hablándolos» para asignarles un lugar como sujetos sociales de discursos particulares, y los procesos productores de subjetividades, que construyen a aquellos individuos como sujetos susceptibles de «decirse». De tal modo, esta perspectiva comprende la construcción de identidades como un conjunto de representaciones —siempre fragmentario y provisorio en virtud de los diferentes contextos históricos y comunicativos-, en el que intervienen individuos que se narran a sí mismos a partir de su conformidad o disconformidad con las posiciones subjetivas socialmente asignadas dentro un orden discursivo y estructura de sentido determinada, pero a la vez otras voces que confirman, confrontan o imponen fronteras a aquellas miradas a partir del estado de las relaciones de poder en una formación discursiva e histórica determinada.

De acuerdo con ese objetivo, se sostienen las siguientes hipótesis: por un lado, que la construcción de las identidades de las víctimas se desarrolló a partir múltiples voces que incluyeron a las de las propias víctimas y sus familiares, pero también otras, como las de actores judiciales, testigos y medios de comunicación, e incluso a perpetradores de aquellos crímenes; en segundo lugar, que los sentidos articulados acerca de esas identidades fueron 
condicionados por la escena comunicativa judicial y sus reglas, pero también por otros registros discursivos no dominados por ella, como los discursos del género político y el moral; finalmente, que las disputas y conflictos implicados en esos procesos de identificación resultan una expresión y un indicador de las luchas políticas más amplias para la reinterpretación del pasado de violencia en aquella sociedad transicional.

En las últimas décadas, diversos trabajos de relevancia han analizado en los procesos de construcción identitaria, apoyados en la figura de la víctima sus implicancias conceptuales, sus efectos sociales y su relación con la administración de justicia en las sociedades contemporáneas. Esa literatura ya ha destacado dos dimensiones que atraviesan este trabajo y se dan por asumidas: las relaciones complejas y no siempre lineales entre las demandas de reconocimiento y las de distribución de justicia (Fraser y Honneth, 2003), y las formas en que las sociedades contemporáneas pueden propender a la victimización en detrimento de la figura de ciudadanía para el reconocimiento o el ejercicio de derechos (Fassin, 2010). Este trabajo, sin embargo, retoma esos debates dentro de un campo de interés particular: su relevancia analítica y centralidad durante la adopción de mecanismos transicionales de justicia, tras procesos masivos de violencia política, vía que distintas sociedades han

adoptado como estrategia, con diverso grado después de la experiencia argentina, para la recomposición de comunidades políticas profundamente heridas. En dichos contextos, las estrategias de reinterpretación del pasado de violencia se manifiestan como parte de las luchas políticas por el sentido del futuro por construir y sus dimensiones determinantes (Jelin, 2002), y en esa medida la construcción de las víctimas resulta relevante como indicador de las tensiones y conflictos políticos en torno a la definición del daño social que se propone reparar.

En cuanto a su marco metodológico, el análisis se sostiene en una metodología cualitativa (Glaser y Strauss, 1999). Se apoya fundamentalmente en el análisis temático de los registros audiovisuales de las audiencias y en las transcripciones taquigráficas de los testimonios; entrevistas en profundidad a distintos protagonistas del evento penal —funcionarios del Poder Judicial y testigos-; materiales de prensa del periodo; y la revisión de las fuentes secundarias disponibles. Cabe aclarar que, en la medida que su objeto son las representaciones sobre las víctimas construidas a lo largo de la instancia judicial, el trabajo no apunta a una reconstrucción de las trayectorias biográficas o las filiaciones políticas concretas, sino a alumbrar las redes y 
Identidades políticas y justicia transicional. Las representaciones sobre los desaparecidos...

claves de sentido comunes que el acontecimiento construyó y puso en escena para un amplio público.

Para las transcripciones taquigráficas, se adoptan las versiones publicadas en El Diario del Juicio, publicación especializada de Editorial Perfil, Argentina, producida para la cobertura del evento penal. Si bien el juicio contó con una considerable cobertura de prensa durante su desarrollo, El Diario del Juicio fue el único medio que publicó en forma literal y completa una amplia serie de testimonios. El juicio fue, a su vez, registrado en forma audiovisual; sin embargo, solo se distribuyeron para difusión clips mudos de video de tres minutos de duración, por lo que el impacto público de las imágenes fue, hasta mediados de la década de 1990, marginal (Feld, 2002). Los registros audiovisuales completos del Juicio a las Juntas se encuentran desde 2013 disponibles para consulta pública en la asociación civil Memoria Abierta y en el Archivo Nacional de la Memoria, en Argentina.

\section{Las metonimias y la escena judicial}

En un sentido general, todo discurso jurídico se organiza mediante la selección deliberada de algunas dimensiones atribuidas a otros fenómenos sociales y piezas discursivas. En el caso de la justicia penal, se trata de la determinación de algunos hechos particulares que resultan tipificables como delitos en el marco del sistema del derecho. A partir de esa selección, la enunciación supuesta por el fallo del tribunal construye una verdad. Para ello, en una audiencia oral, se invocan múltiples voces que, mediante la práctica de la inquisitio como dominio específico del tribunal, los jueces diseccionan, reorganizan y resignifican bajo la forma de una verdad jurídica (Foucault, 1995). Desde ese punto de vista, junto a la restauración de los derechos de las víctimas bajo la figura abstracta del sujeto de derecho, el marco judicial propende a obliterar de la escena jurídica otras dimensiones identitarias sustantivas y es propenso a eludir otros temas sociales no vinculantes a su materia de análisis particular —en el caso de análisis, sopesar las responsabilidades individuales de los miembros de las Juntas en los crímenes cometidos- (González, 1995). De allí se explica, en parte, que en sus intervenciones durante las audiencias los miembros del tribunal hayan restringido parcialmente los cuestionamientos sobre el pasado personal y político de los desaparecidos, así como constreñido las valoraciones y opiniones de las víctimas sobre los hechos revisados.

Pero esa dimensión constrictiva del discurso judicial, de algún modo afín a toda práctica penal, se encontró singularmente afectada durante el 
Juicio a las Juntas, por tratarse de un proceso destinado a sopesar violaciones masivas a los derechos humanos. El contraste entre esos marcos de selección adoptados por el discurso judicial y la experiencia singularizada del terror estatal fue puesto de manifiesto ante el desafío que representaban las desapariciones de personas. Esta práctica brutal y estremecedora irrumpía en los marcos epistémicos entonces disponibles en el derecho. ${ }^{1}$ Frente a ella, el recurso jurídico sustentado en la búsqueda de los cadáveres, como marco de referencia para pensar en los desaparecidos, acentuó la construcción de una relación «metonímica» con las víctimas a partir de sentidos y significantes fragmentarios (Kaufman, 1997). Dicha operación «metonímica» se basaba en la ruptura de la cadena semiótica de asociaciones que ligaba la existencia de ese cuerpo particular a una experiencia vital concreta y polifacética, tanto antes como durante su experiencia en el campo clandestino.

En realidad, estas operaciones de sentido que la sintaxis jurídica invocaba se encontraban relacionadas con otras prácticas sociales más amplias, propias de los crímenes sometidos a discusión. El mecanismo basado en un desplazamiento del objeto era, en efecto, consecuencia de la práctica y el discurso judicial, pero también de las características propias de un sistema represivo que borraba sus huellas. ${ }^{2}$ Estos efectos podían

[ 94 ] encontrarse acrecentados en los testimonios de los sobrevivientes de los centros clandestinos de detención, cuando referían a la existencia de aquellos desaparecidos con los que no habían tenido un contacto extenso. En estos casos, las identidades de esos desaparecidos permanecían dominadas por lo fragmentario y eran verbalizadas únicamente en función de registros sensoriales aislados, por ejemplo, los gritos o los llantos:

[Guillermo] Ledesma [presidente del tribunal en ejercicio]: ¿En esas torturas o en otras, pedían declaraciones sobre algunos aspectos de alguna cuestión?

[Luisa de] Miralles: Sí, a veces insistían sobre distintos temas.

\footnotetext{
${ }^{1}$ Aunque con antecedentes de proyectos que impulsaron la figura de las desapariciones en la década de 1980, sin alcanzar aval parlamentario y utilizada entre 1986 y 1994 en materia legislativa solo a efectos resarcitorios o administrativos, la «desaparición forzada de personas» fue incorporada por primera vez a la legislación argentina en 1995 con un sentido penal, aunque no punitivo, al convalidarse la Convención Interamericana sobre Desaparición Forzada de Personas redactada por la OEA el año anterior (Ley 24556 de 1995).

${ }^{2}$ De allí que esas prácticas fragmentarias pudieran encontrar eco también en la reconstrucción del pasado que víctimas y familiares hacían en otros ámbitos sociales, aunque con usos diferentes, a fines de elaborar un vínculo con el desaparecido y procesar socialmente una «muerte inconclusa» a partir de objetos aislados (da Silva Catela, 2001).
} 
Identidades políticas y justicia transicional. Las representaciones sobre los desaparecidos...

Ledesma: ¿Recuerda alguno en particular? [...].

Miralles: Con respecto a otras personas escuchaba los gritos, las expresiones de dolor, no puedo decir qué es lo que le preguntaban [...] (Diario del Juicio, 1985, junio 4 a, p. 43).

Por contrapartida, como resistencia a ese fenómeno, los sobrevivientes tendían a redimensionar el sentido que la Justicia atribuía a los nombres propios de las víctimas, los que convertían en una reivindicación de la existencia de esos individuos. Y así, los testimonios de los sobrevivientes expresaron un trabajo de memoria que adquiría especial significación. Solo sus voces podían certificar su pasaje por los centros clandestinos, de allí que este trabajo estuviera investido, además, de la condición de deber de memoria y de mandato moral:

[Andrés J.] D’Alessio [presidente del tribunal en ejercicio]: Perdón, ¿podría dar el nombre de las dos parturientas?

[Pablo] Díaz: Sé que eran de Capital Federal, que Dios me perdone, pero no recuerdo. Hace 9 años que lo estoy tratando de recordar (El Diario del Juicio, 1985, junio 11 a, p. 65).

[Adriana Calvo de Laborde: Allí estaban además de las personas que ya nombré [enumera a otras seis personas por sus nombres completos], espero no olvidarme de nadie, aunque más no sea nombrarlas una vez en este tribunal (El Diario del Juicio, 1985, junio 4 b, p. 31).

De ese modo, puede verse que el evento judicial se convirtió también en un escenario en el que comenzaron a disputarse otras estrategias para la reconstrucción y el reconocimiento social de las víctimas. Estas estrategias fueron asumidas por los testimoniantes como una función social asociada a lo que acontecía en tribunales, complementaria — pero distinta- a la función penal. En buena medida, el mandato de esa reconstrucción se asentaba en las características y los discursos negacionistas sobre el sistema represivo clandestino; además, como se verá a continuación, se construyó en virtud de la discusión establecida frente a otros discursos heredados basados en la estigmatización y culpabilización de esas víctimas.

\section{La figura de la "víctima inocente»}

A pesar de las reglas pautadas por el contexto judicial, el juicio fue permeable también a otras instancias de sentido para construir las identidades de las víctimas de la represión con base en su dimensión social, lo que subrayó 
un hecho particular del juicio oral. Los testimonios tuvieron la capacidad de adecuarse, pero a la vez extender el campo de indagación judicial, incorporando nuevos temas y sentidos, tales como las cualidades morales de las víctimas, la exposición de algunas sensaciones y sentimientos, o los deseos y expectativas de justicia; incluso, podían incorporar otros elementos más bien accesorios, tales como simples anécdotas de la vida cotidiana o elementos meramente accidentales que conforman culturalmente la identidad de una persona y la forma en que es percibida por otros:

Ledesma: ¿Puede describirla a esta señorita?

[María Kubik Marcoff de] Lefteroff: Era una chica más o menos como la hermana, la estatura de ella; rubia, unos ojos verdes hermosos, le decían «ojos de gata», ése era el apodo que tenía.

Ledesma: ¿Edad, altura?

Lefteroff: La altura de la hermana, que ahora va a venir la hermana.

Ledesma: No la conocemos, señora.

Lefteroff: Más o menos la altura de ella, muy blanca, rubia, una linda chica y unos ojos muy hermosos, eso sí (El Diario del Juicio, 1985, junio 4 c, p. 40).

Entre estos aspectos culturales que incorporaban los testimonios, hay uno que resultó especialmente significativo en el curso del proceso. Consistió en la proposición, múltiples veces mencionada, acerca de la «inocencia» de las víctimas. En rigor, gran parte de las luchas por el sentido del pasado reciente durante las audiencias, y con ellas la posibilidad de hablar de las víctimas, se encontró apoyada discursivamente en la figura de la «víctima inocente»:

[Teo Van Boven: [... Sé que existía violencia y contra violencia, y que personas inocentes sufrían y morían por este motivo (El Diario del Juicio, 1985, mayo 27 a, p. 4).

[Robert] Cox: Este es uno de los aspectos más diabólicos de la represión, estar dirigido a gente inocente. La idea era hacer aparecer a todos los que criticaban al gobierno como terroristas (El Diario del Juicio, 1985, mayo 27 b, p. 24).

[Alberto Felipe Maly: Cuando me inquirían sobre quiénes eran los que estaban en determinado asado, por ejemplo, yo decía: mire, no sé a qué asado se refieren, porque con mis compañeros de trabajo anualmente voy a muchos asados, siempre se espera una oportunidad para poder festejar algo, y si entre esa gente que asistía a los asados 
Identidades políticas y justicia transicional. Las representaciones sobre los desaparecidos...

había alguien involucrado en alguna organización [guerrillera], eso está fuera de mi conocimiento. A lo que ellos replicaban: Vos no te hagás el inocente (El Diario del Juicio, 1985, junio 11 b, p. 50).

La producción de estos sentidos contaba con una significativa circulación en la cultura política de la transición, que se había expresado, entre otros procesos, en la constitución del informe Nunca Más de 1984 como lieu de mémoire — lugar de la memoria— (Nora, 1984) del terror dictatorial. Allí ya había sido plasmada una inteligibilidad moral de la dictadura en el marco de dos violencias contrapuestas, la revolucionaria y la militar, frente a las cuales la sociedad argentina se proponía como partícipe involuntaria y víctima. A partir de ese paradigma — conocido como la «teoría de los dos demonios»— el Informe y otros discursos sociales retrataron una clasificación del universo de las víctimas en función de su ajenidad a esos grupos. Este deslindamiento impulsó, junto a la denuncia de la violencia política, el imaginario de la «víctima inocente» como una clave característica en las memorias de la transición (Crenzel, 2008).

A lo largo de las audiencias de 1985 la exposición de estos sentidos resultó amplificada por la cobertura del Juicio que realizaron los medios de comunicación. La figura de la «hipervíctima»_las mujeres embarazadas, los niños, los ancianos, los discapacitados- (González, 1995) ocupó un lugar central en las crónicas que los principales periódicos nacionales construyeron sobre los casos tratados en tribunales. A través de estas figuras, se reflejaba un estado extremo de indefensión y de ofensa moral que facilitaba la empatía por parte de un amplio espectro social. Sin embargo, al mismo tiempo estas representaciones se construían a partir de la díada inocente-culpable que había sido utilizada por el discurso dictatorial y, en consecuencia, sin discutir explícitamente el argumento castrense subyacente acerca de que una «culpabilidad» pudiera justificar las violaciones a los derechos humanos (Crenzel, 2011).

Durante el juicio, los testigos militares y otros actores allegados se empeñaron en sostener que una «guerra antisubversiva» había sido necesaria y políticamente legítima, así como los métodos empleados —aunque los casos y acciones concretos fueron sistemáticamente negados ante el tribunal-. Implicaban, a partir de allí, que las víctimas por las cuales los excomandantes estaban siendo juzgados, así como todos aquellos que acusaban a las Fuerzas Armadas por esos actos —incluyendo en esas sospechas a los testigos, a los organismos de derechos humanos, al gobierno nacional y al tribunal- eran 


\section{Diego Galante}

«subversivos». ${ }^{3}$ Por contrapartida, la puesta en relieve de la inocencia de las víctimas apuntalaba la idea de los «excesos» cometidos por los militares con el alegado pretexto de combatir a la «subversión» (Salvi, 2015). De ese modo, la idea de la inocencia reconstruía la figura de la víctima por contraste a la del «enemigo subversivo», la cual era sostenida por los discursos militares, pero bajo un formato cultural que no lograba reivindicar los derechos en forma universal o defender su ciudadanía en un sentido político, es decir, en tanto que capacidad de actuación sobre el mundo social compartido.

Ahora bien, aunque en las representaciones sociales la noción de víctima se asociaba a la inocencia, desde el punto de vista del lenguaje jurídico la idea de la «víctima inocente» representaba un sinsentido. Para el derecho, las víctimas no son inocentes ni culpables, son víctimas de un delito o no lo son. Así lo argumentó, por ejemplo, el fiscal Julio César Strassera durante el juicio, a lo largo de diversas entrevistas brindadas a la prensa durante el desarrollo de las audiencias; ${ }^{4}$ y también lo expresó en su fallo de la Causa 13/84 de 1985 la Cámara Federal, la cual subrayó la manifiesta «antijuridicidad» del plan represivo y su carácter criminal, dado que la supuesta «guerra revolucionaria» contra el «terrorismo» no podía constituir atenuante a las violaciones los derechos humanos cometidas. ${ }^{5}$

Sin embargo, a lo largo de las audiencias, muchos testigos se esforzaron por poner de manifiesto la inocencia de las víctimas y los defensores de los excomandantes por «imputar» o insinuar —al arrojar un manto de sospecha- su «culpabilidad», lo que equivalía a proponer la participación activa o el compromiso ideológico de las víctimas con alguna organización revolucionaria. En la voz de las defensas, este recurso era especialmente sensible cuando prestaba testimonio de los sobrevivientes de los centros clandestinos de detención y podía expresarse en la sensación de que los sobrevivientes eran los acusados y no los excomandantes:

\footnotetext{
${ }^{3}$ Véase, por ejemplo, los testimonios de Salvio Menéndez, Cristino Nicolaides, Rubén Franco (El Diario del Juicio, 1985, mayo 27 c; 1985, mayo 27 d; 1985, mayo 27 e); los descargos de Emilio Massera, Omar Graffigna (El Diario del Juicio, 1985, noviembre 12; 1985, diciembre 10); y la carta cursada al tribunal por Jorge Videla (Clarín, 1985, diciembre 20). Sobre la formación histórica de ese discurso consolidado en los años de dictadura, véase Paula Canelo (2008); sobre las dimensiones filosóficas y ético-políticas adoptadas en la noción de «subversión», véase Hugo Vezzetti (2002) y Pilar Calveiro (1998).

${ }^{4}$ Entre otras, El Diario del Juicio,1985, mayo 27 f; 1985, junio 25; 1985, julio 2.

${ }^{5}$ Véase el Considerando Sexto y los Capítulos I y VI del Considerando Segundo del Fallo la Cámara Federal en la Causa 13/84 de 1985.
} 
Identidades políticas y justicia transicional. Las representaciones sobre los desaparecidos...

Los defensores trataban de ensuciar o invalidar el testimonio, diciendo que nosotros habíamos sido militantes. Mi sensación, estando ahí, era que la acusada era yo. De todas maneras, el tribunal interrumpía cada vez que sentía que ciertas preguntas iban hacia mi militancia o mi responsabilidad en determinados hechos, o hechos de otras personas que yo mencionaba como desaparecidos. Fue muy largo y agotador (comunicación personal, sobreviviente del centro clandestino de detención Escuela de Mecánica de la Armada y testigo durante el Juicio, Buenos Aires, 22 de mayo, 2014).

Esta acusación en clave política se reforzaba por la tendencia a desprestigiar a las víctimas por otras diversas y presuntas faltas morales, dimensiones que también habían operado en forma conjunta durante la dictadura militar (Vezzetti, 2002). Por ejemplo, durante las audiencias se endilgó a una víctima el hecho de convivir con su pareja sin haber contraído matrimonio. Y hubo situaciones extremas, como el caso de una testigo sobre quien se insinuó que había sostenido relaciones sexuales consentidas con su torturador. ${ }^{6}$ La escena del juicio se trasladaba así de su objeto y habilitaba una instancia discursiva donde se retomaba el juzgamiento de otros presuntos delitos y faltas cívicas o morales, precisamente, aquellos argumentos en que se habían sostenido las estrategias de justificación del terrorismo de Estado durante la dictadura militar.

No es de extrañar las víctimas o sus familiares intentaran también rebatir la argucia de los militares y pusieran de relieve las cualidades morales positivas de las víctimas, lo que al mismo tiempo se transformaba en una reivindicación y en un homenaje público a la luz de la escucha que brindaba el juicio oral. En muchas ocasiones, el tipo de valores morales que era recalcado por afectados directos, familiares y conocidos, podía coincidir con aquellos que eran sostenidos por el discurso militar, y se tendía de ese modo a descalificar, en sus propias categorías, la «imputación» de culpabilidad moral que era insinuada desde la posición castrense:

[Nemí Aníbal] Lebed: Entra quien sería el jefe [...], «Póngase contra la pared» [...]. Le digo: "Yo soy un jefe de familia honorable, soy argentino, cristiano, católico, nacionalista. Entiendo que esto es un atropello» (El Diario del Juicio, 1985, diciembre 24, p. 566).

\footnotetext{
${ }^{6}$ Véase las intervenciones de los defensores del 27 de mayo y del 2 de julio (El Diario del Juicio, 1985, junio 4 c, p. 7; agosto 27, p. 324).
} 
De estas diversas maneras, el juicio funcionaba, junto a su curso penal, como un escenario y caja de resonancia que amplificaba otros discursos y sentidos producidos en campos distintos de representación social. En ese fórum, los discursos sobre las identidades de las víctimas del terrorismo de Estado se construyeron como un objeto particular. Surgido como un tema superpuesto y diferenciado a los que promovía en forma dominante el tribunal - centrado en el universo de la acción criminal de los excomandantes- esos sentidos evocaban las disputas y representaciones más generales existentes en aquella sociedad argentina que revisaba su pasado. Así, las representaciones sobre las víctimas del terrorismo de Estado eran el resultado de un entrecruzamiento entre voces y géneros diversos —el jurídico, el político y el moral- y condiciones históricas determinadas, poniendo de manifiesto que los procesos penales no solo producen y discuten enunciados jurídicos, sino que brindan además la posibilidad de vislumbrar características y conflictos centrales de las sociedades que los construyen (Ginzburg, 1993).

De ese modo, más allá de los mecanismos estructurantes propios de todo ritual jurídico, así como el orden establecido en la jerarquía de los enunciados y actos que lo integran (Sarrabayrouse, 2011; Marí, 1993), el proceso penal de 1985 se convertía también en una escena —actualizada, modalizada, en pugna por resignificar - de aquella sociedad argentina más amplia que debatía su pasado en la transición. En ese escenario, la figura de la «víctima inocente», por ejemplo, se construía en un orden discursivo no dominado por la instancia judicial, aunque ciertamente potenciado por la visibilidad y legitimidad social de esta.

\section{Las identidades políticas}

Esas maneras de presentar las identidades de las víctimas durante las audiencias crearon dificultades adicionales para la enunciación de las identidades políticas de las víctimas. Al respecto, cuatro fueron los tipos característicos desarrollados durante el juicio.

El primero y más común de ellos era el que refería a la inexistencia de una identidad política concreta, es decir, la desvinculación de cualquier tipo de colectivo político: 
Identidades políticas y justicia transicional. Las representaciones sobre los desaparecidos...

[Alberto Felipe] Maly: A mí me arrestan por una supuesta relación con montoneros, ${ }^{7}$ relación que yo honestamente no tenía [...]. Después surgió, una de las palabras, que yo era un perejil; es algo así como Pérez el Gil. ${ }^{8}$ Esa fue la aclaración que me dio este señor. Entonces, tratando de analizar las cosas, me dije si yo soy un perejil, un don nadie, entonces por qué estoy aquí. Bueno, ésa es una de las cosas que uno maquinaba o pensaba cuando estaba en estas circunstancias (El Diario del Juicio, 1985, mayo 11 b, p. 50).

En segundo lugar, podía encontrarse en algunas ocasiones la referencia a una identidad mediada por la militancia social y antidictatorial de masas, aunque desvinculada de las actividades partidarias:

[Adriana Calvo de] Laborde: Yo no militaba en ningún partido político, yo trabajaba en la Asociación de Docentes e Investigadores de la Facultad de Ciencias Exactas [...]. Todos sabían cuál era mi posición política, no era ningún secreto. Yo fui profundamente antigolpista, dentro de mis posibilidades, con mis compañeros de trabajo [...]. Efectivamente, me opuse a ello, dentro de mi lugar de trabajo (El Diario del Juicio, 1985, junio 4 b, p. 33).

Una tercera forma de referirse a la militancia incluía elementos partidarios concretos, dados por la filiación a los partidos políticos tradicionales o sectores de esos partidos —Unión Cívica Radical, Partido Justicialista, Juventud Peronista, Democracia Cristiana, entre otros-:

[Carlos] Muñoz: [En las sesiones de tortura] me preguntaban por gente que había militado conmigo en la Juventud Peronista, [...] hasta setiembre del '77, momento en el cual me abro o me voy porque [...] sabía la situación de aquella época, o sea que toda persona que tuviera alguna idea política que no fuera la de los mentores del Proceso de Reorganización Nacional, era peligrosa (El Diario del Juicio, 1985, noviembre 5, p. 454).

La última modalidad se situaba en el terreno de la distancia y la ajenidad. Se trataba de las referencias a las organizaciones políticas revolucionarias y se caracterizó primordialmente por el dispositivo de enunciación que

\footnotetext{
${ }^{7}$ Montoneros, con actividades públicas desde 1970, fue una de las principales organizaciones de la guerrilla revolucionaria en Argentina (Gillespie, 1982).

${ }^{8}$ En la jerga de las fuerzas de seguridad argentinas, un «perejil» es aquella persona que, sin responsabilidad concreta frente a un hecho delictivo, purga penas por otros que sí la tienen.
} 
construían los testigos con base en la relación de otredad con esos espacios políticos. Precisamente, los tres tipos anteriores de identidad se encontraron marcados por una relación de no identidad con este «otro». Ese otro político se definía así por aproximación, de una manera negativa, pero no llegaba a presentarse nunca en sus dimensiones y contenidos políticos concretos más que por la caracterización estereotipada que realizaban los testigos militares y las defensas. Las identidades políticas revolucionarias aparecían como algo dado o sobrentendido. Como esto «dado» era paradigmáticamente lo tematizado por el discurso de los militares y defensores, sus fronteras aparecían dispuestas por el arbitrio militar. Así, su figura por excelencia era la del «terrorismo-subversivo», y generalmente se manifestaba bajo la forma de una caricaturización:

Marutián (defensor de Viola): Solicito se le pregunte al testigo respecto a cómo caracterizaría la acción desarrollada por las fuerzas subversivas, y la consecuente acción emprendida por las Fuerzas Armadas para enfrentarlas [...].

[Cristino] Nicolaides: ${ }^{9}$ Como profesión militar, personalmente no tengo ninguna duda, de que esto fue una guerra [...]. Para ser sintético y emplear términos que ya están muy conocidos: la subversión buscaba la conquista del poder para imponer una ideología de izquierda totalmente ajena a las tradiciones, al sentir y al sistema de vida nacional, era algo distinto que se quería, se pretendía imponer para el país, ése era el objetivo político por el cual se buscaba el poder dentro de la Nación (El Diario del Juicio, 1985, mayo 27 d, p. 22).

La referencia a esos colectivos políticos en el resto de los testimonios, especialmente de víctimas y familiares, consistía en forma predominante a una invocación meramente nominativa —Montoneros, subversión, terrorismo, entre otros- Generalmente, aludía a personas vistas en los centros clandestinos pero ajenas a la propia experiencia vital y, por lo tanto, no se ahondaba en los contenidos de esas identidades. De esta manera, la identidad de «los otros» se resolvía proponiéndola como una exterioridad de difícil aprehensión. A tal punto resultaban escasas las referencias de víctimas y familiares a conocidos que pudieran haber participado efectivamente en alguna agrupación política revolucionaria, que en una ocasión las defensas intentaron signar el proceso judicial entero en la «confesión» que

\footnotetext{
${ }^{9}$ Representante del Ejército en la Junta Militar entre 1982 y la transición a la democracia. No alcanzó a ser investigado en el Juicio a las Juntas, pero fue tardíamente condenado por múltiples crímenes contra la humanidad (Procuraduría de Crímenes Contra la Humanidad, 2018).
} 
Identidades políticas y justicia transicional. Las representaciones sobre los desaparecidos...

bajo tortura una testigo habría escuchado gritar a su esposo en un centro clandestino de detención y desaparición. ${ }^{10} \mathrm{Y}$ durante la declaración del excapellán Christian Von Wernich —condenado en 2007 tras haberse probado su participación en secuestros, torturas y homicidios cometidos en los centros clandestinos de su pastoral - se presentó la pertinencia a alguna «organización subversiva» como un hecho que acreditaba un secreto sentimiento de culpabilidad religiosa a ser expiado mediante el sacramento católico de la confesión. ${ }^{11}$

Por un lado, esa forma de tematizar la militancia en la izquierda de la década de 1970 obliteraba que la participación directa en acciones insurgentes armadas había sido solo una forma, radical, entre el amplio espectro de acciones políticas y mecanismos de identificación ideológica compartidas por distintos grupos de actores, con diversas gamas de participación en la escena colectiva, todas ellas afectadas de modo similar por la experiencia represiva (Oberti y Pittaluga, 2016). Por el otro lado, merced a ese abordaje en la escena judicial, las identidades políticas de la propuesta revolucionaria no solo carecieron de una voz enunciativa propia en el transcurso de las audiencias; además, se presentaron como algo sobre lo que no se debía o no se podía hablar mucho. Este efecto fue reforzado, adicionalmente, por la propia estrategia narrativa del discurso judicial, que apuntaba a desautorizar las preguntas o declaraciones de la opinión política, impropias o irrelevantes al proceso penal en sí, en este caso, la filiación política de víctimas y testigos. De ese modo, el simple nombre de una organización guerrillera podía llegar a parecer incluso un tabú. ${ }^{12}$

El resultado general fue una especie de sentido común vagamente verbalizado y cuyo abordaje resultaba conflictivo para la mayoría de los actores del debate judicial, excepto para los militares y las defensas aunque mediado, en este último caso, por una ideología estereotipizante y profundamente antidemocrática-. Así, la escena del juicio escindía las posibilidades de establecer nuevas representaciones sobre las identidades políticas de los desaparecidos, posibilidades que se encontraban ocluidas por la articulación de un discurso estigmatizante sobre la «subversión», junto con el silencio propio del tratamiento jurídico sobre ellas.

10 Véase el testimonio de Cristina Temperoni (E1 Diario del Juicio, 1985, septiembre 3).

11 Véase el testimonio de Cristian Von Wernich (El Diario del Juicio, 1985, junio $11 \mathrm{c}$ ).

12 Véase, por ejemplo, el testimonio de Alberto Cruz Lucero, donde solicita permiso al tribunal para nombrar a la organización Montoneros (Amato, 1985, mayo 27). 


\section{A modo de conclusión: las identidades y los derechos}

En el proyecto político de la transición a la democracia en Argentina, el Juicio a las Juntas revestía un sentido performativo que excedía la determinación de las responsabilidades penales de los militares implicados. En gran parte fue concebido como un «ritual extraordinario» que, a través de la puesta en foco de un pasado desgarrador, se propuso reordenar el imaginario y la cultura política existentes en vías a una consagración simbólica de la democracia y los valores asociados al Estado de derecho (Kaufman, 1991; González, 2004). Sin embargo, los sentidos atribuidos en la práctica a las ideas del Estado o el sujeto de derecho siempre están determinados por la formación histórica particular que los produce y no por su eficacia normativa dentro del derecho explícitamente consagrado (Rorty, 1986). Precisamente, es ese contexto social el que provee los materiales a partir de los cuales se funda la «sensibilidad legal» del tribunal como manera de comprender lo real y los temas sociales considerados relevantes (Geertz 1994; Tiscornia, 2000).

En el caso de análisis, el proceso penal estuvo atravesado por múltiples procesos sociales de disputa de significados. Entre esos procesos sociales más amplios se inscribieron la necesidad y el llamado a la construcción de [104] una memoria colectiva sobre la violencia política más compatible con el orden democrático, aunque mediada por el conflictivo contexto político de la transición. También, el hecho de que en ese contexto la oclusión de las identidades y filiaciones políticas permitía un distanciamiento frente a esa conflictividad, la cual permitía el reconocimiento de aquellas víctimas a partir de dimensiones morales profundamente arraigadas en los que diferentes sectores sociales podían reconocerse, sin por ello tener que coincidir necesariamente en una denuncia en clave política del pasado dictatorial (Vecchioli, 2005). En este aspecto, el despliegue de la figura de la «víctima inocente» durante las audiencias y las miradas estereotipizantes sobre el «terrorismo subversivo» constituyeron un síntoma.

Pero resultaba imposible que las políticas de sentido basadas en la probidad moral de las víctimas no conllevaran una determinada operacionalización de la idea de derechos. Y así, las caracterizaciones desarrolladas durante las audiencias tuvieron implicancias en las concepciones existentes sobre el cuerpo de derechos reivindicable en el plano de la cultura política. En este caso, construyendo, junto a la reducción de las fronteras de los derechos civiles de las víctimas según su tipo de participación en la vida 
pública, un desplazamiento de los derechos políticos, en tanto capacidad de reflexión o actuación sobre la vida compartida. En esta dirección, el Juicio a las Juntas se expresó como una arena en la que, puede decirse, se confrontaron las dimensiones formales clásicas de la idea de ciudadanía, principalmente basadas en el carácter universal de los derechos al interior de un cuerpo político y, con ellos, la idea del sujeto de derecho (Marshall, 1998), y otros sentidos históricos y coyunturales propios de la cultura de época.

De algún modo, al tiempo que el juicio fue exitoso al instaurar determinados sentidos en el plano jurídico, cuyas consecuencias perduran hasta los juicios actuales (Lorenzetti y Kraut, 2011), fue también la comparecencia de múltiples voces ante la Justicia que se expresaron en la mediación, actualización y reproducción de una serie social más amplia de sentidos (Garapon, 2002, p. 96). Finalmente, en virtud de su relevancia política y social, el juicio tuvo un efecto catalizador y propagador para esa serie de representaciones en el ámbito de la cultura. Desde ese punto de vista, el juicio constituyó un acto en el que los discursos de la Justicia, potenciados por una demanda social, impulsaron determinadas representaciones sobre las víctimas y la violencia de Estado, al mismo tiempo que se convirtió en un foro que amplificaba y cristalizaba públicamente una pluralidad de saberes y disputas no regidos por la enunciación judicial.

Si bien desde fines de la década de 1990 nuevas referencias a una identidad militante y la reivindicación de una memoria de la lucha comenzaron a manifestarse públicamente a partir de algunas intervenciones políticas y culturales en Argentina (Otero, 2010), las representaciones construidas en la década de 1980 continuaron siendo dominantes para grandes sectores de la sociedad argentina contemporánea (Born y Galante, 2013), aspecto que en el Juicio a las Juntas desempeñó un rol central. La pervivencia de esas disputas da cuenta de la centralidad de los conflictos en torno a las identidades de las víctimas en los procesos de violencia política masiva, discusiones que trascienden la órbita de los tribunales y la duración y efectos concretos del trámite penal.

\section{Referencias bibliográficas}

1. Aboy Carlés, Gerardo. (2001). Las dos fronteras de la democracia: La reformulación de las identidades políticas de Alfonsín a Menem. Rosario: Homo Sapiens, Fundación Ross. 
2. Acuña, Carlos; González Bombal, Inés; Jelin, Elizabeth; Landi, Oscar; Quevedo, Luis Alberto; Smulovitz, Catalina y Vacchieri, Adriana. (1995). Juicio, castigos y memorias: derechos humanos y justicia en la política argentina. Buenos Aires: Nueva Visión.

3. Amato, Alberto. (1985, mayo 27). Miedos y corajes frente a los jueces. EI Diario del Juicio. Recuperado de https://cdadum.files.wordpress.com/2013/08/eldiario-del-juicio-01.pdf

4. Argentina. Cámara Nacional de Apelaciones en lo Criminal y Correccional de la Capital Federal. Causa 13/84. (9 de diciembre de 1985). Texto completo de la sentencia dictada el 9 de diciembre de 1985 por la excelentísima Cámara Nacional de Apelaciones en lo Criminal y Correccional Federal de la Capital Federal en la causa 13 del año 1984 seguida al Tte. Gral. (r.) Jorge Rafael Videla ... [et al.]. Buenos Aires: Imprenta del Congreso de la Nación. Recuperado de http://www.derechos.org/nizkor/ arg/causa13/

5. República Argentina. (1986). Causa originariamente instruida por el Consejo Supremo de las Fuerzas Armadas en el cumplimiento del Decreto 158/83 del Poder Ejecutivo Nacional. En: Fallos de la Corte Suprema de Justicia de la Nación. Fallos de la Corte Suprema de Justicia de la Nación. Tomo 309, volumen II (pp. 1689-1925). Buenos Aires: Corte Suprema de Justicia de la Nación.

6. Argentina. Poder Ejecutivo Nacional. Decreto 158/83. (13 de diciembre de 1983). Orden presidencial de procesar a las juntas militares. Recuperado de http:// www.desaparecidos.org/nuncamas/web/document/nacional/decr158.htm

7. Argentina. Poder Legislativo. Ley 24556. (13 de septiembre de 1995). Apruébase la Convención Interamericana sobre Desaparición Forzada de Personas, aprobada por la Asamblea General de la Organización de Estados Americanos (OEA) en su 24. a Asamblea General. Recuperado de http://servicios.infoleg.gob.ar/infoleglnternet/ anexos/25000-29999/28394/norma.htm

8. Procuraduría de Crímenes Contra la Humanidad. (2018). Dossier de sentencias pronunciadas en juicios de Lesa Humanidad en Argentina. Buenos Aires: Ministerio Público Fiscal de la Nación.

9. Arfuch, Leonor. (2008). El primer relato público del horror. En: Crítica cultural entre política y estética (pp. 105-130). Buenos Aires: FCE.

Born, Diego y Galante, Diego. (2013). Representaciones actuales sobre la última dictadura militar en la Provincia de Buenos Aires. x Jornadas de Sociología. Universidad de Buenos Aires, Buenos Aires. Recuperado de http://cdsa.aacademica. org/000-038/4

10. Calveiro, Pilar. (1998). Poder y desaparición: los campos de concentración en la Argentina. Buenos Aires: Colihue.

11. Canelo, Paula. (2008). El Proceso en su laberinto: la interna militar de Videla a Bignone. Buenos Aires: Prometeo. 
Identidades políticas y justicia transicional. Las representaciones sobre los desaparecidos...

12. Ciancaglini, Sergio y Granovsky, Martín. (1995). Nada más que la verdad: el juicio a las Juntas. La guerra sucia desde el golpe hasta las autocríticas militares. Buenos Aires: Planeta.

13. Clarín. (1985, diciembre 20). Devolvió la Cámara Federal una carta enviada por Videla. P. 7.

14. Crenzel, Emilio. (2008). La historia política del Nunca Más: La memoria de las desapariciones en la Argentina. Buenos Aires: Siglo xxı.

15. Crenzel, Emilio. (2011). Los desaparecidos entre la culpabilidad y la inocencia: una díada compartida. En: Pérez, Germán; Aelo, Oscar y Salerno, Gustavo (coords.). Todo aquel fulgor. La política argentina después del neoliberalismo (pp. 161-172). Buenos Aires: Nueva Trilce.

16. Da Silva Catela, Ludmila. (2001). No habrá flores en la tumba del pasado: la experiencia de reconstrucción del mundo de los familiares de desaparecidos. La Plata: Al Margen.

17. El Diario del Juicio. (1985, mayo 27 a). Testimonio del señor Teo Van Boven, ex director de Derechos Humanos de la ONU. 23 de abril de 1985. Pp. 3-5. Recuperado de https://cdadum.files.wordpress.com/2013/08/el-diario-del-juicio-01.pdf

18. El Diario del Juicio. (1985, mayo 27 b). Testimonio del señor Robert Cox. Periodista. 26 de abril de 1985. P. 24. Recuperado de https://cdadum.files.wordpress. com/2013/08/el-diario-del-juicio-01.pdf

19. El Diario del Juicio. (1985, mayo 27 c). Testimonio del contraalmirante (RE) Salvio Menéndez. 23 de abril de 1985. Pp. 8-10. Recuperado de https://cdadum.files. wordpress.com/2013/08/el-diario-del-juicio-01.pdf

20. El Diario del Juicio. (1985, mayo $27 \mathrm{~d}$ ). Testimonio del teniente general (RE) Cristino Nicolaides. 26 de abril de 1985. Pp. 20-22. Recuperado de https://cdadum. files.wordpress.com/2013/08/el-diario-del-juicio-01.pdf

21. El Diario del Juicio. (1985, mayo 27 e). Testimonio del almirante (RE) Rubén Óscar Franco. 26 de abril de 1985. Pp. 22-23. Recuperado de https://cdadum.files. wordpress.com/2013/08/el-diario-del-juicio-01.pdf

22. El Diario del Juicio. (1985, mayo 27 f). El Juicio del Siglo. Suplemento número presentación a El Diario del Juicio. Strassera. Entrevista a Julio César Strassera. Pp. 10-11. Recuperado de https://cdadum.files.wordpress.com/2013/08/el-diario-deljuicio-01.pdf

23. El Diario del Juicio. (1985, junio 4 a). Testimonio de la señora Luisa de Miralles, empleada. 2 de mayo de 1985. Pp. 42-43. Recuperado de https://cdadum. files.wordpress.com/2013/08/el-diario-del-juicio-02.pdf

24. El Diario del Juicio. (1985, junio 4 b). Testimonio de la señora Calvo de Laborde, licenciada en Física. 29 de abril de 1985. Pp. 29-33. Recuperado de https:// cdadum.files.wordpress.com/2013/08/el-diario-del-juicio-02.pdf

25. El Diario del Juicio. (1985, junio 4 c). Testimonio de la señora Luisa de Miralles, empleada. 2 de mayo de 1985. Pp. 42-43. Recuperado de https://cdadum. files.wordpress.com/2013/08/el-diario-del-juicio-02.pdf 
26. El Diario del Juicio. (1985, junio 11 a). Testimonio del señor Pablo Díaz, empleado. 9 de mayo de 1985. Pp. 62-66. Recuperado de https://cdadum.files. wordpress.com/2013/08/el-diario-del-juicio-03.pdf

27. El Diario del Juicio. (1985, junio 11 b). Testimonio de Alberto Felipe Maly, electricista. 6 de mayo de 1985. Pp. 49-52. Recuperado de https://cdadum.files. wordpress.com/2013/08/el-diario-del-juicio-03.pdf

28. El Diario del Juicio. (1985, junio 11 c). Testimonio del señor Cristian Von Wernich, capellán de la Policía de la Provincia de Buenos Aires. 8 de mayo de 1985. Pp. 56-59. Recuperado de https://cdadum.files.wordpress.com/2013/08/el-diario-deljuicio-03.pdf

29. El Diario del Juicio. (1985, junio 25). Agosti es tan responsable como Massera. Entrevista a Julio César Strassera. P.8. Recuperado de https://cdadum.files.wordpress. com/2013/08/el-diario-del-juicio-05.pdf

30. El Diario del Juicio. (1985, julio 2). Los defensores son los que buscan politizar el juicio. Entrevista a Julio César Strassera. P. 8. Recuperado de https://cdadum.files. wordpress.com/2013/08/el-diario-del-juicio-06.pdf

31. El Diario del Juicio. (1985, agosto 27). Testimonio de la señora Elena Alfaro. Estudiante. 2 de julio de 1985. Pp. 314-324. Recuperado de https://cdadum.files. wordpress.com/2013/08/el-diario-del-juicio-14.pdf

32. El Diario del Juicio. (1985, septiembre 3). Testimonio de la señora Cristina Temperoni, empleada. 5 de julio de 1985. Pp. 343-346. Recuperado de https:// cdadum.files.wordpress.com/2013/08/el-diario-del-juicio-15.pdf

33. El Diario del Juicio. (1985, noviembre 5). Testimonio de señor Carlos Muñoz, periodista. 23 de julio de 1985. Pp. 452-464. Recuperado de https://cdadum.files. wordpress.com/2013/08/el-diario-del-juicio-24.pdf

34 El Diario del Juicio. (1985, noviembre 12). Testimonio de Emilio Massera. 3 de octubre de 1985. Pp. 1-7. Recuperado de https://cdadum.files.wordpress. com/2013/08/el-diario-del-juicio-25.pdf

35. El Diario del Juicio. (1985, diciembre 10). Testimonio de Omar Graffigna. 16 de octubre de 1985. Pp. 5-6. Recuperado de https://cdadum.files.wordpress. com/2013/08/el-diario-del-juicio-30.pdf

36. El Diario del Juicio. (1985, diciembre 24). Testimonio del señor Nemí Aníbal Lebed, jardinero. 9 de agosto de 1985. Pp. 566-568. Recuperado de https://cdadum. files.wordpress.com/2013/08/el-diario-del-juicio-31.pdf

37. Fassin, Didier. (2010). La raison humanitaire. Une histoire morale du temps présent. Paris: Seuil.

38. Feld, Claudia. (2002). Del estrado a la pantalla: las imágenes del juicio a los excomandantes en Argentina. Madrid: Siglo xxı.

39. Feld, Claudia y Franco, Marina (dirs.). (2015). Democracia hora cero: actores, políticas y debates en los inicios de la posdictadura. Buenos Aires: FCE. 
Identidades políticas y justicia transicional. Las representaciones sobre los desaparecidos...

40. Franco, Marina. (2015). La «teoría de los dos demonios» en la primera etapa de la posdictadura. En: Feld, Claudia y Franco, Marina (dirs.). Democracia hora cero: actores, políticas y debates en los inicios de la posdictadura (pp. 23-80). Buenos Aires: FCE.

41. Fraser, Nancy y Honneth, Axel. (2003). Redistribution Or Recognition?: A Political-philosophical Exchange. New York: Verso.

42. Foucault, Michel. (1995). La verdad y las formas jurídicas. Barcelona: Gedisa.

43. Galante, Diego. (2014). El "Juicio a las Juntas» en la escena política argentina. En: Bufano, Sergio y Lotersztain, Israel (eds.). Lucha Armada en la Argentina, año 10 (pp. 92-107). Buenos Aires: Ejercitar la Memoria.

44. Galante, Diego. (2015). Los debates parlamentarios de Punto Final y Obediencia Debida: el Juicio a las Juntas en el discurso político de la transición tardía. Clepsidra, 2 (4), pp. 12-33.

45. Galante, Diego. (2017). "La Constitución y la prudencia»: los tres niveles de responsabilidad para el juzgamiento de las violaciones a los derechos humanos en la transición argentina. Sociohistórica, 40, pp. 1-17. https://doi. org/10.24215/18521606e036

46. Garapon, Antoine. (2002). La justicia y la inversión moral del tiempo. En: Barret-Ducrocq, Françoise (dir.). ¿Por qué recordar? (pp. 90-100). Barcelona: Granica.

47. Geertz, Clifford. (1994). Conocimiento local: hecho y ley en la perspectiva comparativa. En: Conocimiento local. Ensayos sobre la interpretación de las culturas (195-262). Barcelona: Paidós.

48. Gillespie, Richard. (1982). Soldiers of Perón: argentinian's Montoneros. Oxford: Oxford University.

49. Ginzburg, Carlo. (1993). El juez y el historiador: consideraciones al margen del proceso Sofri. Madrid: Anaya \& Mario Muchnik.

50. Glaser, Barney y Strauss, Anselm (1999). Discovery of Grounded Theory: Strategies for Qualitative Research. New York: Routledge.

51. González Bombal, Inés. (1995). Nunca más: el juicio más allá de los estrados. En: Acuña, Carlos et al. Juicio, castigos y memorias. Derechos humanos y justicia en la política argentina (pp. 193-216). Buenos Aires: Nueva Visión.

52. González Bombal, Inés. (2004). La figura de la desaparición en la re-fundación del Estado de Derecho. En: Novaro, Marco y Palermo, Vicente (comps.). La historia reciente: Argentina en democracia (pp. 115-131). Buenos Aires: Edhasa.

53. Hall, Stuart. (1995). Fantasy, Identity, Politics. En: Carter, Erica; Donald, James \& Squites, Judith (eds.). Cultural Remix: Theories of Politics and the Popular (pp. 6370). London: Lawrence \& Wishart.

54. Hall, Stuart y du Gay, Paul (comps.). (2003). Cuestiones de identidad cultural. Buenos Aires-Madrid: Amorrortu.

55. Jelin, Elizabeth. (2002). Los trabajos de la memoria. Madrid: Siglo XxI.

56. Kaufman, Alejandro. (1997). Notas sobre desaparecidos. Confines, 4, pp. 29-34. 
57. Kaufman, Ester. (1991). Desnaturalización de lo cotidiano: el ritual jurídico en el juicio a los excomandantes. En: Guber, Rosana (dir.). El salvaje metropolitano: A la vuelta de la antropología postmoderna, reconstrucción del conocimiento social en el trabajo de campo (pp. 327-358). Buenos Aires: Legasa.

58. Lorenzetti, Ricardo y Kraut, Alfredo. (2011). Derechos humanos: justicia y reparación. Buenos Aires: Sudamericana.

59. Marí, Enrique. (1993). Papeles de filosofía. Buenos Aires: Biblos.

60. Marshall, Thomas H. (1998). Ciudadanía y clase social. En: Marshall, Thomas H. y Bottomore, Tom. Ciudadanía y clase social (pp. 15-82). Madrid: Alianza.

61. Nino, Carlos. (2006). Juicio al mal absoluto. Buenos Aires: Ariel.

62. Nora, Pierre. (1984). Entre mémoire et Histoire. En: Les Lieux de mémoire (pp. XVII-XLII). Paris: Gallimard.

63. Oberti, Alejandra y Pittaluga, Roberto. (2016). Apuntes para una discusión sobre la memoria y la política de los años 60/70 a partir de algunas intervenciones recientes. Sociohistórica, 38, pp. 1-22.

64. O'Donnell, Gillermo. (1997). Democracia en la Argentina. Micro y macro. En: Contrapuntos. Ensayos escogidos sobre autoritarismo y democratización (pp. 133146). Buenos Aires: Paidós.

65. Otero, Rocío. (2010). La repolitización de la historia de los sesenta y setenta: una nueva etapa en la representación del pasado reciente. En: Medvescig, Claudia; Otero, Rocío; Salvi, Valentina y Villa, Alejandro. La sociedad argentina hoy frente a [110] los años '70 (pp. 66-111). Buenos Aires: Eudeba.

66. Rorty, Richard. (1986). Solidarity or Objectivity? In: Ranchman, John \& West, Cornel (eds.). Post-analytic philosophy (pp. 3-19). New York: Columbia University.

67. Salvi, Valentina. (2015). Guerra, subversivos y muertos: un estudio sobre las declaraciones de militares en el primer año de democracia. En: Feld, Claudia y Franco, Marina (dirs.). Democracia hora cero: actores, políticas y debates en los inicios de la posdictadura (pp. 153-194). Buenos Aires: FCE.

68. Sancinetti, Marcelo. (1988). Derechos humanos en la Argentina post dictatorial. Buenos Aires: Manuel Lerner.

69. Sarrabayrouse Oliveira, María José. (2011). Poder judicial y dictadura. El caso de la morgue judicial. Buenos Aires: Ediciones del Puerto y CELS.

70. Sikkink, Kathryn. (2011). The Justice Cascade: How Human Rights Prosecutions are Changing World Politics. New York: W. W. Norton \& Company.

71. Tiscornia, Sofía. (2000). Seguridad y cultura de la violencia: el teatro de la furia. Revista Encrucijadas, 1 (1), pp. 49-59.

72. Vecchioli, Virginia. (2005). La nación como familia. Metáforas políticas del movimiento argentino de derechos humanos. En: Frederic, Sabina y Soprano, Germán (comps.). Cultura y política en etnografías sobre la Argentina (pp. 24-269). Quilmes: Universidad Nacional de Quilmes.

73. Vezzetti, Hugo. (2002). Pasado y presente. Guerra, dictadura y sociedad en la Argentina. Buenos Aires: Siglo xxı. 